\title{
Trends in tidal power development
}

\author{
Alberto Boretti ${ }^{1, *}$ \\ ${ }^{1}$ Mechanical Engineering Department, College of Engineering, Prince Mohammad Bin Fahd University, Al Khobar, Saudi Arabia
}

\begin{abstract}
Tidal energy has been around for almost 2,000 years, as the first Tide Mills date the Romans times. Tidal power generation then emerged in the 1960s, with the construction of the $240 \mathrm{MW}$ La Rance power station, a still working example of good renewable energy initiative, permitting electricity production at very competitive costs since now more than 54 years. Unfortunately, apart from the construction in 2011 of a similar plant based on the tidal range technology, the 254 MW Sihwa Lake power station, almost nothing else happened in the real world for tidal energy, apart from very small or demonstration plants. While the future is certainly towards tidal streams/currents technologies rather than tidal range technologies, as tidal currents turbines may also be used for oceanic currents installations, these technologies are still in their infancy, as apart from their theoretical performance, every other aspect of a submerged power plant operation needs further developments.
\end{abstract}

\section{Introduction}

Tidal energy is the result of the gravitational influence of the moon and the sun on the ocean waters. Differences between high and low tides create tidal currents in coastal areas, that can be harvested with free stream turbines similar to wind turbines, or more traditional turbines placed in tidal barrages. Mills driven by the tidal rise and fall have been built since the Medieval Age, with some examples dating back to the time of the Romans. Until recently, there was in the world only one plant of decent size producing tidal electricity, La Rance Tidal Power Plant, a 240 MW plant completed in 1966 and still operational. Fig.1 presents an image of an old Tidal Mill in Portugal, and Fig.2 presents a view of the La Rance Tidal Power Plant.

The plant of La Rance is built in a very favorable environment for the harvesting of tidal energy. It required the construction of a $145 \mathrm{~m}$ long barrage with six gates and a $164 \mathrm{~m}$ long dike to produce a basin area of $22 \mathrm{~km}^{2}$. In the location featuring the highest tidal range in France, $8.2 \mathrm{~m}$ on average. The barrage also serves the purpose of transport from one side to the other of the Rance river.

There are many estimations for the total energy available worldwide from tides. According to [1], the technically harvestable tidal energy resource from areas close to the coast, "is estimated by several sources at 1 terawatt (TW)". [2] suggests a more reasonable theoretical global ocean tidal energy resource of 90 gigawatts (GW), however, then suggesting an annual generation of 800 TWh for capacity factors above unity (a generating power of $90 \mathrm{GW}$ produces at the most $90 \cdot 365 \cdot 24=$ $788,400 \mathrm{GWh}$ or $788.4 \mathrm{TWh}$ ).
So far, La Rance Tidal Power Plant has worked with capacity factors of about 0.26 , which are very far from unity, as tidal ranges or currents are very well known to be variables in time.

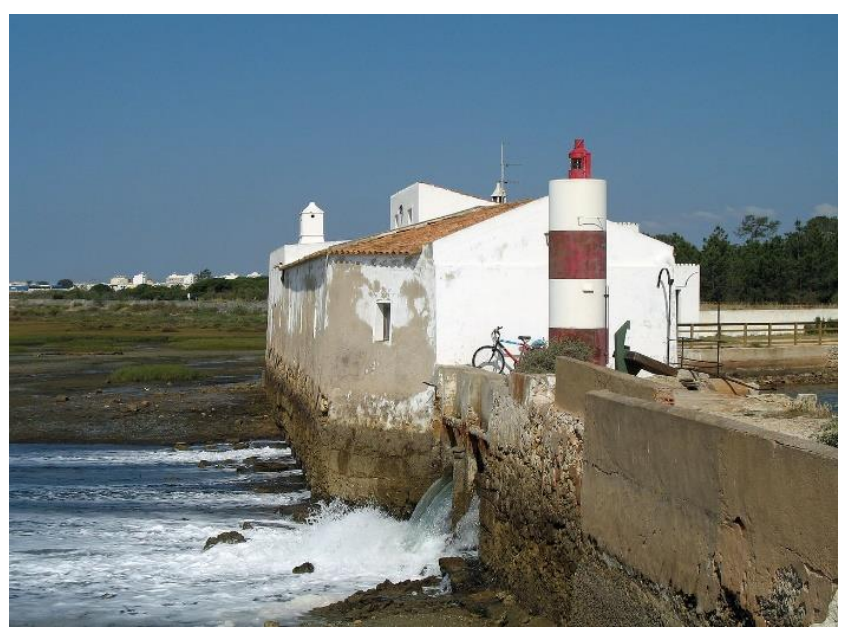

Fig. 1 - Tide Mill in Portugal. Image from. en.wikipedia.org/wiki/Tide_mill\#/media/File:Olhao_Tide_Mill .jpg

In 2011, the 254 MW Sihwa Lake Tidal Power Station was added. Fig. 3 presents a view of the Sihwa Lake Tidal Power Station. Same of La Rance, it features the barrage tidal range technology.

Alternative solutions are based on tidal stream hydrokinetic turbines not requiring any barrage, up to now limited to demonstration projects. Marine hydrokinetic turbines have significant similarities with wind turbines, apart from the operation in a much harsher environment with also smaller velocities but much larger densities and are receiving large coverage in theoretical works.

*Corresponding author: a.a.boretti@gmail.com 
Here below I summarize the status of tidal energy by examining electricity production and costs. Of existing and future projects.

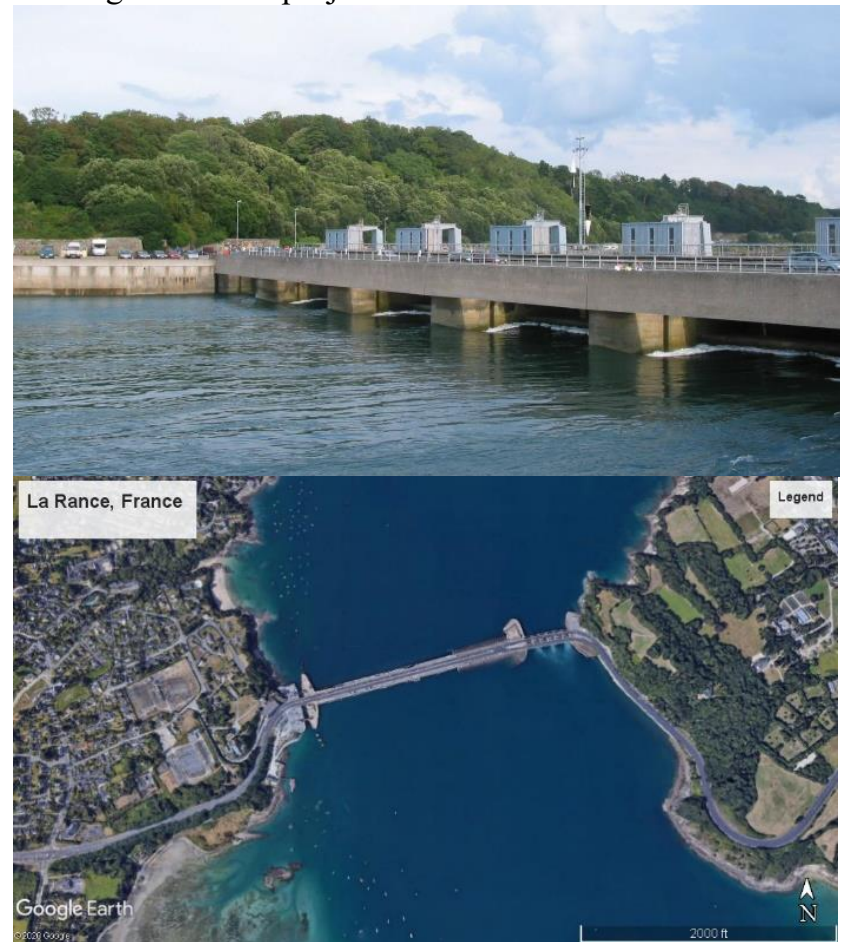

Fig. 2 - Images of La Rance Tidal Power Plant, in France. Top image is from

upload.wikimedia.org/wikipedia/commons/6/63/Rance tidal $p$ ower plant.JPG, Bottom image is from Google Earth.

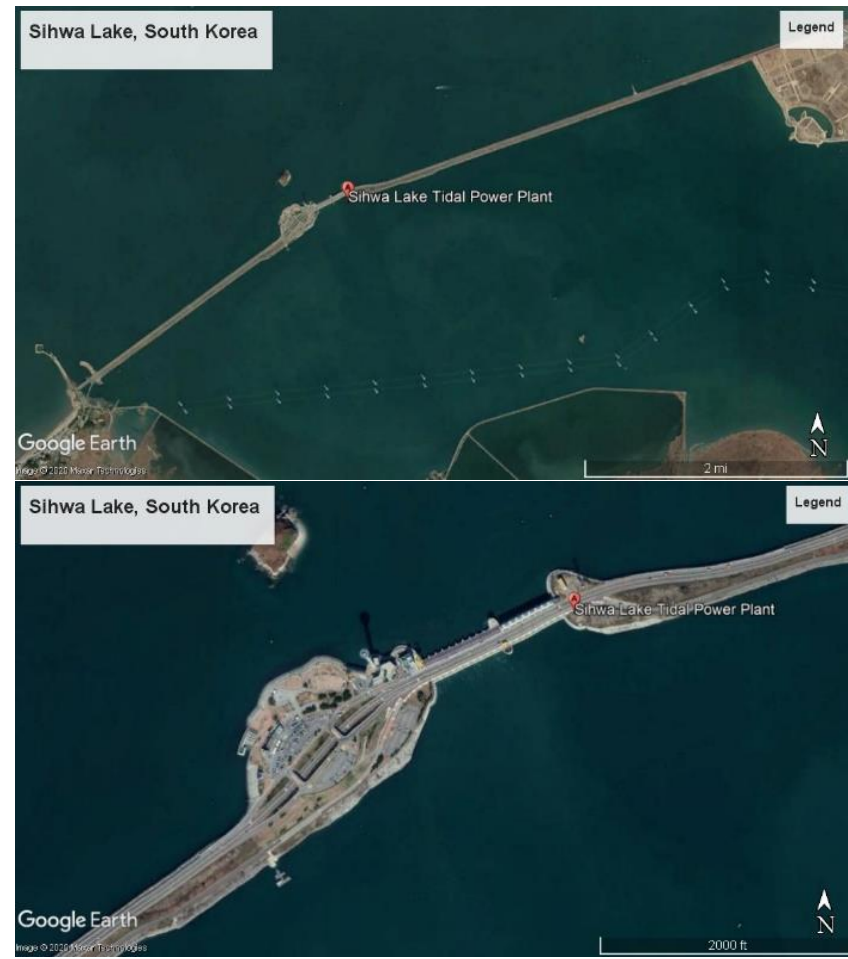

Fig. 3 - Images of Sihwa Lake Tidal Power Station in South Korea, both from Google Earth.

\section{Tidal plants in the world}

There are in the world basically 2 large tidal power plants operational, plus few large tidal power projects around the world for a globally negligible worldwide contribution to the energy mix. Power-technology.com [3] lists 5 large tidal power plants, including 3 operational, and 1 so far limited to a demonstration project and 1 put on hold.

Sihwa Lake Tidal Power Station, in South Korea, is the world's largest tidal power station with $254 \mathrm{MW}$ of installed capacity. Completed in 2011 , it uses a $12.5 \mathrm{~km}$ long seawall constructed previously built for flood mitigation and irrigation. It uses 10 submerged bulb turbines of capacity 25.4 MW. Power is only generated on the tidal inflow. Gates are used for the outflow. The annual generation capacity of the facility is $552.7 \mathrm{GWh}$ [3]. The capacity factor is 0.25 .

La Rance Tidal Power Plant, in France, that was completed in 1966, is the oldest and second-largest tidal power plant. It is $240 \mathrm{MW}$ with an annual generation capacity of $540 \mathrm{GWh}$ [3]. Larger figures, also above the Sihwa Lake Tidal Power Station are provided by other sources [4]. La Rance uses classic Kaplan turbines. The project required the construction of the barrage. It uses 24 reversible bulb turbines of capacity $10 \mathrm{MW}$ each. Electricity is produced during inflow and outflow but differently. [4] mention an average annual electricity production of $550 \mathrm{GWh}$ (ebb tide) plus $60 \mathrm{GWh}$ (rising tide), but then they state only $550 \mathrm{GWh} /$ year of electricity production Capacity factor is 0.26 .

According to [5], ebb generation (direct turbining): occurs for $60 \%$ of the time. Reverse pumping (reservoir towards the sea) never occurs. Flood generation (reverse turbining) occurs 2 to $6 \%$ of the time. Direct pumping (sea towards reservoir) occurs 15 to $20 \%$ of the time. Free flow through the turbines orifices (mainly sea towards reservoir) occurs $20 \%$ of the time (when $0.3 \mathrm{~m}<$ Head $<1.2 \mathrm{~m}$ ). No pumping required when the tidal range is above 7 or $10 \mathrm{~m}$. However, [5] also adds Now, flood generation only during high tides (tidal range $>$ $12 \mathrm{~m}$ ) and maximum pumping capacity $56 \mathrm{MW}$ by contract.

Unfortunately, while data exists of resource and power generation from small pilot plants such as a single $1 \mathrm{MW}$ turbine [6], there is no detailed high-frequency information available for the power generation from Sihwa Lake Tidal Power Station or La Rance Tidal Power Plant.

It is indeed an unfortunate circumstance that electricity production data of renewable energy plants are mostly missing worldwide. While the US EIA [7] publishes since 2001 the data of electricity production of every plant but with a low (monthly) frequency, the Australian AEMO [8] is the only organization in the world publishing data of electricity production with 5 minutes sampling frequency. Unfortunately, nor the US, not Australia, have tidal power stations.

The other major projects listed by Powertechnology.com [3] are all under construction.

One of the projects is the $240 \mathrm{MW}$ Swansea Bay Tidal Lagoon, in the UK. This project involved the construction of a long sea wall to create a lagoon. It was supposed to use reversible bulb turbines to generate 
power with the rise and fall of tides. Supposed to be already completed, but the current plan has been rejected by the UK Government.

Another project is the smaller MeyGen Tidal Energy Project, also in the UK (Scotland). This is a project not involving the construction of a lagoon, but using underwater tidal turbines (tidal stream generator). Supposed to be the world's largest underwater tidal turbines project, in between the many delays it now features in phase one just $41.5 \mathrm{MW}$ turbines on the seabed, for a total of $6 \mathrm{MW}$. It is reported that the 4 turbines produced $13.8 \mathrm{GWh}$ in 2019 , up to the $8 \mathrm{GWh}$ reported for 2018 , for a capacity factor also of 0.26 .

The last project considered in [3] is the Annapolis Royal Generating Station, in Canada. It has an installed capacity of $20 \mathrm{MW}$ and generates $50 \mathrm{GWh}$ of electricity annually. This is the third world's largest plant. The capacity factor is 0.28 . The plant was completed in 1984 . It uses a causeway previously built and it is made up of a single turbine and gates. The turbine is operated by the water rushing into the sea.

This is the status of tidal power in the world, 1 large plant (240 MW) completed in 1966, 1 large plant (254 MW) more recently added in 2011 , then only one small plant (20 MW) completed in 1984, all featuring the tidal barrage technology, then a longer list of only planned plants plus technology demonstration studies.

\section{Tidal technologies}

While real-world examples are minimal, many tidal energy principles are being considered in the literature. Tidal energy is considered for example in [9], [10], [11] or [1]. [1] for example lists 3 current technologies for tidal energy generation.

The first category is a tidal range, that uses a barrage to harvest energy from the height difference between high and low tide. This is the well-known and proven case of Annapolis Royal Generating Station, La Rance Tidal Power Plant, and Sihwa Lake Tidal Power Station. [1] also mention new tidal range ideas for generating power such as tidal 'lagoons', 'reefs', or 'fences', and low-head tidal barrages, however still far from being proven technologies.

In principle, the energy available from a tidal barrage is dependent on the volume of water filling the basin. In case the tidal energy is harvested after the basin is filled at high tide by discharging the volume of water through the turbines at low tide, according to [12] it is (tidal outflow power generation)

$E=g \cdot \rho \cdot(\mathrm{S} \cdot \mathrm{h}) \cdot(1 / 2 \cdot \mathrm{h})$

where $\mathrm{S}$ is the surface of the basin, average between high and low tides, $\mathrm{h}$ is the tidal range, $\mathrm{g}$ is the gravity acceleration, and $\rho$ is the density of the water. The term $1 / 2 \cdot h$ originates from the fact that the average hydraulic head across the turbines is reducing as the basin empties through the turbines. This way, if there are 2 high tides and 2 low tides every day, every day there is the opportunity to produce twice the above electricity.
In the case of La Rance, it is $\mathrm{S}=22.5 \mathrm{~km}^{2}, \mathrm{~h}=8 \mathrm{~m}$ average tidal range, and from $\mathrm{g}=9.81 \mathrm{~m} / \mathrm{s}^{2}$ and $\rho=1,025$ $\mathrm{kg} / \mathrm{m}^{3}$, and $2 \cdot 365 \cdot \mathrm{E}=5.285 \cdot 10^{15} \mathrm{~J}$, or $1.47 \cdot 10^{3} \mathrm{GWh}$. Being the actual production of $540 \mathrm{GWh}$, the ratio actual/theoretical energy production is 0.368 .

In the case of La Rance power station, the schedule of power generation was very different, especially at design. Electricity was generated when emptying the basin, and also when filling the basin, with sometimes pumping operation included, and turbines operated with a range of hydraulic heads across the barrage and the help of gates [5]. Opposite, the Sihwa Lake power station only generates power on tidal inflow only (tidal inflow power generation) with an unknown schedule.

More properly, for a tidal range turbine, it is:

$$
\begin{aligned}
& P=\eta \cdot \frac{1}{2} \cdot \rho \cdot A \cdot U^{3} \\
& \eta=\eta_{a} \cdot \eta_{m} \cdot \eta_{e}
\end{aligned}
$$

with $\rho$ water density, A rotor area, $U$ speed of the water, and $\eta$ the power coefficient, with $\eta_{\mathrm{a}}$, mechanical energy, $\eta_{\mathrm{m}}$ transmission efficiency and $\eta_{\mathrm{e}}$ mechanical to electric energy conversion efficiency. $U$ is linked to the instantaneous head across the barrage according to the formula

$$
U=\beta \cdot \sqrt{2 \cdot g \cdot h} \mathrm{w}
$$

ith $\beta$ a proportionality factor. Once a profile $\mathrm{P}(\mathrm{U})$ is given in the tabulated form, then the theoretical electricity production is:

$E=\int P(U(t)) d t$

The second category is a tidal current or tidal stream. The rising and falling of the tide are accompanied by tidal currents that may be significant approaching bays or estuaries. The incoming tidal current into bays and estuaries is the flood current, and the outgoing tidal current is the ebb current. There are many new devices based on the vertical or horizontal axis, free or enclosed (ducted) turbines, proposed to harvest flood, ebb or both currents [1]. There have been few single turbine technology demonstration studies, with the demonstration of arrays of turbines still missing. The largest project in this category is the MeyGen Tidal Energy Project. Tidal current or tidal stream turbines are also intended to harvest the energy of oceanic currents. The exploitation of the energy of oceanic currents is by far even less developed than the exploitation of tidal energy [13]. Tidal currents (same of oceanic currents) technologies have the advantage over barriers to affect much less the environment, but until the first large scale plant will be built and operated, it is extremely difficult to factor the many other issues embedded in this solution.

The third category mentioned by [1], is pure speculations of "hybrid applications" that are described as tidal technologies combined with new infrastructure for coastal zones. While both the Annapolis Royal Generating Station and the Sihwa Lake Tidal Power Station are sort of "hybrid applications", enjoying infrastructure previously built, what the "hybrid 
applications" are in practice, and how they perform, it is hard to say, as no full-scale prototype has been built yet.

An advantage of tidal range and tidal current energy is that they are relatively predictable and minimally influenced by the weather.

\section{Tidal energy costs}

Cost indications, as in case of the tidal range they depend on the specific barrage, and in the other case there is simply no data to estimate cost and production over the life span of the plant.

It must be added that renewable energy literature suffers from the spreading of over-optimistic numbers that are not challenged even if openly wrong. Most of the renewable energy scientists seem to have little idea about the concepts of curiosity, skepticism, openmindedness that should request challenging politically correct but technically wrong views.

As an example, IRENA [1] correctly stated in Table 1, reproduced below, that the costs of the $240 \mathrm{MW}$ La Rance Tidal Power Plant and the 254 MW Sihwa Lake Tidal Power Station were respectively 817 and 298 million \$US. However, in the same Table, they also made a major mistake, proposing construction costs per $\mathrm{kW}$ that were 10 (ten) times smaller than what they were.

As $1 \mathrm{MW}=1000 \mathrm{~kW}$, a cost of 817 million \$US for $240 \mathrm{MW}$ of power would have translated into a cost of $3,404 \$ / \mathrm{kW}$ and not $340 \$ / \mathrm{kW}$, and similarly, a cost of 298 million \$US for 254 MW of power would have translated into a cost of $1,173 \$ / \mathrm{kW}$ and not $117 \$ / \mathrm{kW}$. The mistaken costs per $\mathrm{kW}$ of the installed capacity were repeated in other parts of the document where it is written: 'The construction costs for 'La Rance' were around USD 340 per kilowatt (/kW) (2012 value; commissioned in 1966), whilst the Sihwa barrage was constructed for USD 117/kW in 2011."

The fact that the idea of a cost of only 340 or 117 $\$ / \mathrm{kW}$ even if openly wrong has never been challenged, and the wrong numbers have been re-proposed by many, [14] to [17] just to name a few, is a clear indication that performance and cost having consensus, are nevertheless untrustworthy.

La Rance, now 54 years old and still doing well, has been a major technological success. I can estimate the cost per kWh of electricity produced for La Rance and Sihwa Lake by using their actual construction costs, a life span of 25 years as standard or also 50 years (La Rance is operational since 54 years), with the only uncertainty of the O\&M costs, ordinary and extraordinary, that are difficult to be assessed. For example, the 10 years' renovation of La Rance of the late 1990s had a cost of 78 million US\$ [18]. For La Rance, during the 54 years of life, stators had to be replaced starting in the 1970 s, and after 30 years, bulb renovation was also needed. As full details of costs are unavailable.

As shown in Table 2, by prudentially assuming O\&M costs of $30 \mathrm{US} \$ / \mathrm{kW} / \mathrm{yr}$., the cost per $\mathrm{kWh}$ of $\mathrm{La}$ Rance can be estimated to as low as 0.04 \$US per kWh, and the cost of Sihwa Lake even less, 0.02 \$US per $\mathrm{kWh}$, if a life span of the plant of 50 years is considered.

Table 1 - Costs of existing tidal barrage projects according to IRENA [1]. The construction cost per kW is mistaken.

\begin{tabular}{|l|c|c|c|c|c|}
\hline \multicolumn{1}{|c|}{ Barrage } & Country & $\begin{array}{c}\text { Capaclity } \\
\text { (MW) }\end{array}$ & $\begin{array}{c}\text { Power } \\
\text { generation } \\
\text { (GWh) }\end{array}$ & $\begin{array}{c}\text { Construction } \\
\text { costs } \\
\text { (million USD) }\end{array}$ & $\begin{array}{c}\text { Construction } \\
\text { costs per kW } \\
\text { (USD/kW) }\end{array}$ \\
\hline $\begin{array}{l}\text { Operating } \\
\text { La Rance }\end{array}$ & France & 240 & 540 & 817 & 340 \\
\hline Sihwa Lake & Korea & 254 & 552 & 298 & 117 \\
\hline
\end{tabular}

Table 2 - Costs of La Rance and Sihwa Lake tidal range stations.

\begin{tabular}{|l|r|r|r|r|}
\hline & \multicolumn{1}{|l}{ La Rance } & \multicolumn{1}{l}{ Sihwa Lake } & La Rance & Sihwa Lake \\
\hline Number of years & 25 & 25 & 50 & 50 \\
\hline Power [MW] & 240 & 254 & 240 & 254 \\
\hline Construction cost/kW [US\$/kW] & 3400 & 1170 & 3400 & 1170 \\
\hline Capacity factor & 0.26 & 0.24 & 0.26 & 0.24 \\
\hline Electricity [kWh] & $1.37 \mathrm{E}+10$ & $1.34 \mathrm{E}+10$ & $2.73 \mathrm{E}+10$ & $2.67 \mathrm{E}+10$ \\
\hline Construction cost total [US\$] & $8.16 \mathrm{E}+08$ & $2.97 \mathrm{E}+08$ & $8.16 \mathrm{E}+08$ & $2.97 \mathrm{E}+08$ \\
\hline Construction cost/kWh [US\$/kWh] & 0.06 & 0.02 & 0.03 & 0.01 \\
\hline O\&M/kW/yr. [US\$/kW/yr.] & 30 & 30 & 30 & 30 \\
\hline O\&M cost total [US\$] & 180000000 & 190500000 & 180000000 & $1.91 \mathrm{E}+08$ \\
\hline Cost total [US\$] & $9.96 \mathrm{E}+08$ & $4.88 \mathrm{E}+08$ & $9.96 \mathrm{E}+08$ & $4.88 \mathrm{E}+08$ \\
\hline Total cost/kWh [US\$/kWh] & 0.07 & 0.04 & 0.04 & 0.02 \\
\hline
\end{tabular}

There is no other recent renewable energy source that has permitted so far numbers that are close to those delivered by La Rance over the already 54 years of operation. Unfortunately, good sites such as La Rance or Sihwa Lake are in short supply around the world. 
Estimated costs for other barrage technologies vary significantly from one source to the other, depending on the specific conditions (both barrage extension and tidal range). Estimated costs for alternative technologies such as a tidal stream, are much higher, and even more sensitive to O\&M costs.

Tidal stream turbines, same of oceanic current turbines, are similar to wind turbines, but with the aggravation of operation in a much harsher environment. If wind turbines may fail after 20 years of operation, it is hard to believe that tidal stream turbines may operate for 25 years without any issue.

Opposite to the barrage, tidal range technology that is proven to work, and only suffers from the lack of many good sites plus the environmental impact, the tidal current / tidal stream technologies are still in the demonstration stage, so proper cost estimates are impossible. While the deployment of more turbines may certainly reduce their cost, the O\&M costs including their eventual replacement in part or as the whole turbine during the 25 years of the life of the plant are impossible to be estimated from statistical samples of zero plants built and operated.

According to [1], costs of tidal energy in purely speculative European studies range from 0.19 and 0.25 US\$ 2020/kWh, while current demonstration projects suggest Levelized Cost of Electricity (LCOE) more likely in the range from 0.27 and 0.51 US\$ $2020 / \mathrm{kWh}$, that is very expensive compared to solar PV, solar concentrator or wind.

\section{Hydrodynamic of MHK}

The further development of tidal energy will depend on the success of marine hydrokinetic (MHK) turbines, which may also help with the harvesting of oceanic currents. Opposite to the well-established Kaplan turbines for tidal barrages, nothing is granted for covered in marine hydrokinetic turbines still in their infancy. The most developed aspect of marine hydrokinetic turbines is their hydrodynamic, and their mechanical power production.

If physical turbines featuring the proposed aerodynamic, but with all the ancillaries, from pitch control to nacelle for electricity generation, may then work under the extremely harsh environment, and for how long, and with which frequency and costs of maintenance, is a different story than only prolonged testing of prototypes will address. Fig. 4 is an image of a Seagen double rotor MHK turbine.

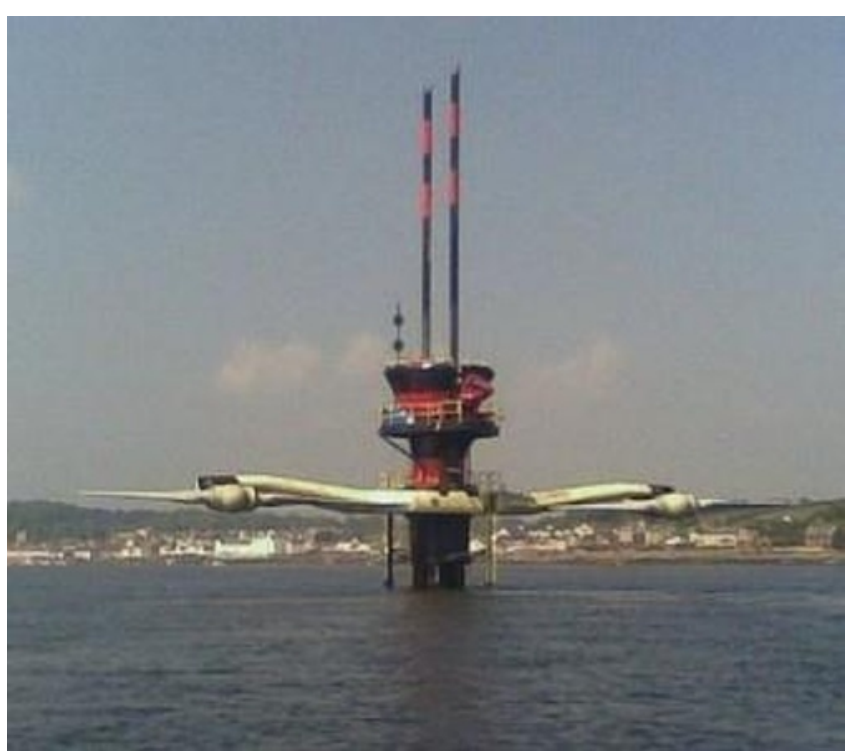

Fig.4 - MHK turbine Seagen with rotors raised. Image from

upload.wikimedia.org/wikipedia/commons/e/e1/Seagenr aised.jpg

The only consolidated aspect of deployment of marine hydrokinetic turbines to harvest tidal energy (or the energy of oceanic currents) is their principle of operation and estimation of electricity production for a given resource in the axial flow design mutated from wind turbines.

NREL [19] proposes the use of the same aerodynamic tools for the design of horizontal-axis wind and general marine hydrokinetics turbines including oceanic current turbines.

While the incompressible flow equations certainly well represent both applications, the rotor blade profiles for currents may differ considerably from the profiles used in wind turbines, as the rotor must be made much smaller, but also much stronger. For a tidal current turbine, equations are (2), (3) and (5). In this case, U must be measured.

From the data of the resource, and the power curve of the turbine, the computation of electricity production is then straightforward. This can be done by using an excel file, or even by using the SAM software [20], that in the latest beta version also features marine hydrokinetic.

The marine energy tidal model in SAM requires a table of tidal current flow versus column depth to characterize the tidal resource and a table of electrical power versus tidal current speed to characterize the energy converter.

SAM also requires data specifying expected losses due to the setup of multiple energy converters into an array, resource prediction uncertainty, electrical transmission, and other sources.

Installation and operating costs for the Levelized cost of electricity (LCOE) as well as other financial parameters can also be introduced.

SAM uses for the tidal energy resource a probability distribution function of surface tidal current velocities. 
In case parameters are unknown, SAM applies a default $2 \%$ transmission loss and $5 \%$ array/device downtime loss. Fig. 5 presents sample inputs and outputs parameters for SAM simulations.
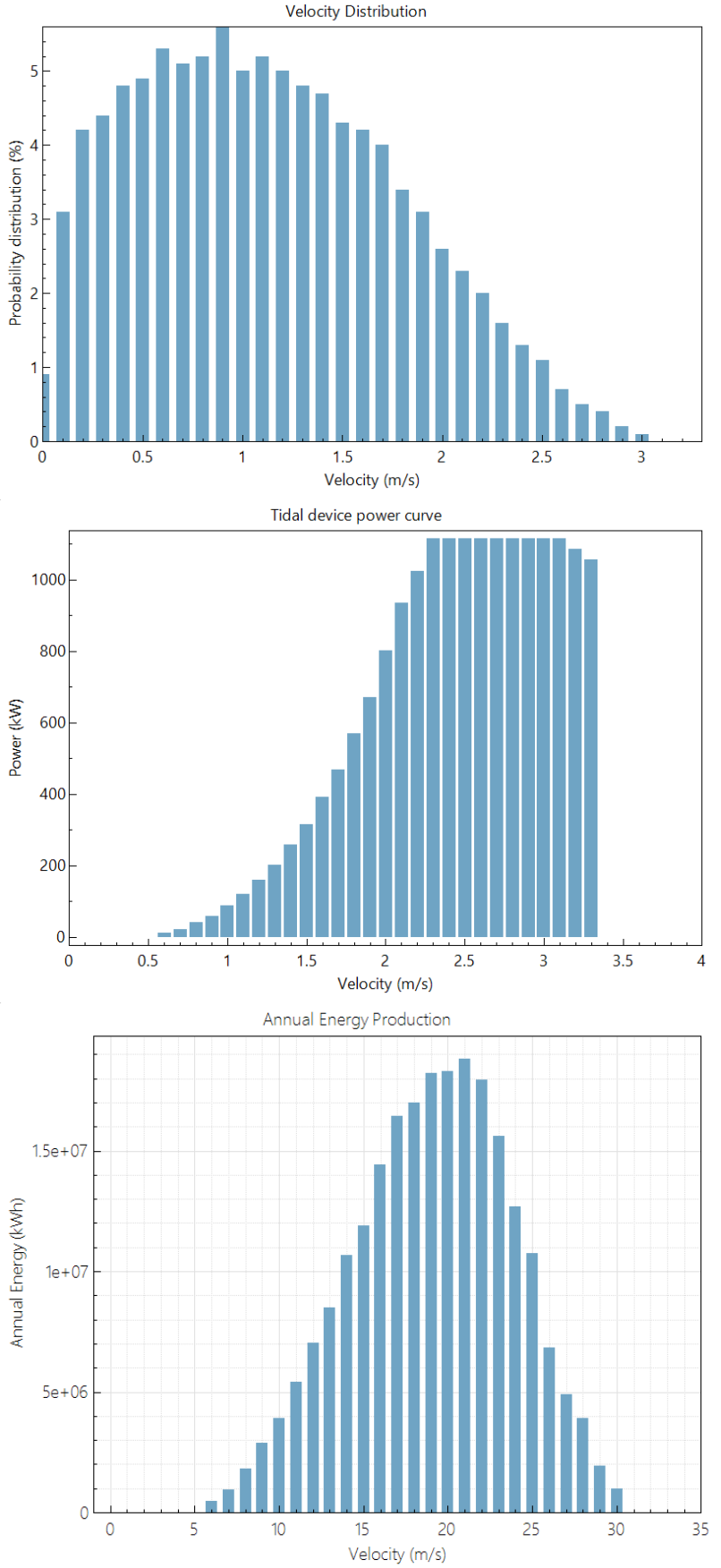

Fig. 5 -Sample SAM simulations for an MHK device of power $111.5 \mathrm{~kW}$. The annual capacity factor is 0.22 . The SAM scale in the third image is wrong, as velocities are 0.5 to $3.0 \mathrm{~m} / \mathrm{s}$ and not 5 to $30 \mathrm{~m} / \mathrm{s}$.

While having resource vs. time in the year could permit the much more valuable computation of electricity production vs. time (electricity has more value in certain times, and less value in others) the approach used only permits a statistical output of electricity produced,

While performance estimation at the nacelle of every turbine is relatively straightforward, similarly to transmission losses, downtimes are impossible to be predicted with accuracy, not having a supporting database of real-world prolonged operation of the specific devices. Everything related to costs is similarly high speculative.

\section{Conclusions}

40 years ago, as a young engineering student, I analyzed tidal energy and the project of La Rance in a report. My conclusion was that tidal energy exploitation, in the specific location of La Rance, was a great idea, however very difficult to be repeated in other locations, where the economic and environmental costs for the barrage are much larger, while the enclosed basin and the tidal range are much less. The La Rance power station is still working great after 54 years, providing relatively predictable renewable energy electricity at 0.04 US\$ per $\mathrm{kWh}$, a number well below the cost of electricity delivered by every other renewable energy initiative. Apart from Sihwa Lake, not that much happened since then. While technologies based on tidal (and oceanic) currents are certainly promising, these technologies are very far from being a solution for today's' energy problems, as they need significant further research and development and the solution to many challenges.

\section{Acknowledgments}

The author did not receive any funds and has no conflict of interest to declare.

\section{References}

www.irena.org/documentdownloads/publications/tidal_e nergy_v4_web.pdf

[2] Australian Government Geoscience Australia, Ocean Energy, n.d., www.ga.gov.au/energy/other-renewableenergy-resources/ocean-energy.html

[3] www.power-technology.com/features/featuretidalgiants-the-worlds-five-biggest-tidal-power-plants4211218/

[4] www.weamec.fr/en/blog/record_synthesis/tidal-powerplant-of-la-rance/

tethys.pnnl.gov/sites/default/files/publications/La_Rance Tidal_Power_Plant_40_year_operation_feedback.pdf

[6] Lewis, M., Mc̄Naughton, J., Márquez-Dominguez, C., Todeschini, G., Togneri, M., Masters, I., Allmark, M., Stallard, T., Neill, S., Goward-Brown, A. and Robins, P., Power variability of tidal-stream energy and implications for electricity supply..Energy 2019, 183, pp.1061-1074.

[7] www.eia.gov/electricity/datá/browser

[8] www.nemweb.com.au/

[9] www.nrel.gov/docs/fy17osti/66079.pdf

[10] www.nrel.gov/docs/fy16osti/66097.pdf

[11] www.nrel.gov/docs/fy16osti/66866.pdf

[12] Lamb, H., 1994. Hydrodynamics (6th ed.). Cambridge University Press, p. 260. 
[13] Boretti, A., State-of-the-art of MW-level capacity oceanic current turbines, Nonlinear Engineering. Modeling and Application, 2020, in press.

[14] Guerrero-Lemus, R. and Shephard, L.E., 2017. LowCarbon Energy in Africa and Latin America. Springer.

[15]

www.fluid.mech.ntua.gr/flow2014/documents/G_Aggidi s_Tidal\%20Energy.pdf

[16] www.power-technology.com/features/tidal-energy-cost/

[17] Christina I. Reichert, John Virdin, 24 - Energy from the Sea from Part VI - Policies for Ocean Governance, in Climate Change and Ocean Governance. Politics and Policy for Threatened Seas, Edited by Paul G. Harris, Cambridge University Press. doi.org/10.1017/9781108502238.024

[18] www.powerengineeringint.com/1996/11/01/la-rancetidal-plant-starting-10-year-renovation/

[19] National Renewable Energy Laboratory, NWTC Information Portal, n.d., nwtc.nrel.gov/technologytype/marine-hydrokinetics

[20] sam.nrel.gov/ 